\title{
Evaluation of Nitrite Radical Scavenging Properties of Selected Zimbabwean Plant Extracts and Their Phytoconstituents
}

\author{
Fadzai Boora, ${ }^{1}$ Elaine Chirisa, ${ }^{2}$ and Stanley Mukanganyama ${ }^{2,3}$ \\ ${ }^{1}$ School of Pharmacy, College of Health Sciences, University of Zimbabwe, Mt. Pleasant, Harare, Zimbabwe \\ ${ }^{2}$ Department of Biochemistry, University of Zimbabwe, Mt. Pleasant, Harare, Zimbabwe \\ ${ }^{3}$ Biomolecular Interactions Analyses Group, Department of Biochemistry, University of Zimbabwe, P.O. Box MP 167, \\ Mt. Pleasant, Harare, Zimbabwe
}

Correspondence should be addressed to Stanley Mukanganyama; smukanganyama@medic.uz.ac.zw

Received 6 December 2013; Accepted 4 March 2014; Published 6 April 2014

Academic Editor: Vassiliki Oreopoulou

Copyright (C) 2014 Fadzai Boora et al. This is an open access article distributed under the Creative Commons Attribution License, which permits unrestricted use, distribution, and reproduction in any medium, provided the original work is properly cited.

\begin{abstract}
Oxidative stress resulting from accumulation of reactive oxygen species has been associated with disease. The search for natural antioxidants of plant origin is necessitated by the side effects associated with synthetic antioxidants currently available. The objective of the study was to determine the antioxidant activity of Combretum zeyheri, Combretum platypetalum, and Parinari curatellifolia extracts by determining nitrite radical scavenging ability. The nitrite radical scavenging assay was used to evaluate the antioxidant potential of the extracts. The total flavonoid content of $P$. curatellifolia methanol extract was determined by the aluminium calorimetric method. The aqueous and ethanolic leaf extracts of C. zeyheri, C. platypetalum, and $P$. curatellifolia extracts exhibited nitrite radical scavenging activity. The results show the scavenging activity in the order of potency: P. curatellifolia $>$ C. platypetalum $>$ C. zeyheri with concentration values of $103 \mu \mathrm{g} / \mathrm{mL}, 158 \mu \mathrm{g} / \mathrm{mL}$, and $188 \mu \mathrm{g} / \mathrm{mL}$ for the ethanol extracts and $92.5 \mu \mathrm{g} / \mathrm{mL}, 97.5 \mu \mathrm{g} / \mathrm{mL}$, and $198 \mu \mathrm{g} / \mathrm{mL}$ for the water extracts, respectively. P. curatellifolia ethanol extract was the most potent and the total flavonoid content was estimated to be $0.4 \pm 0.05 \mathrm{mg} / \mathrm{g}$ quercetin and could account for the activity. Thus, our findings provide evidence that C. zeyheri, C. platypetalum, and $P$. curatellifolia leaf extracts could be potential sources of natural antioxidants.
\end{abstract}

\section{Introduction}

Oxidation in living organisms is essential for the generation of energy during catabolism but these metabolic processes result in the continuous production of free radicals and reactive oxygen species (ROS) in vivo. Free radicals or more generally ROS are highly reactive species that are generated by cells during respiration and cell-mediated immune functions [1]. Free radicals are also generated through environmental pollutants, cigarette smoke, automobile exhaust, radiation, and pesticides [2]. The instability and reactivity of free radicals due to the lone electron in the outer shell can cause them to attack specific biomolecules in the body such as protein and lipids [3]. Normally, there is a balance between the quantity of free radicals generated in the body and the antioxidant mechanisms which scavenge/quench these free radicals preventing them from causing deleterious effects in the body [2]. The antioxidant mechanisms include endogenous and exogenous systems such as catalase and vitamin antioxidants, respectively. When the generation of free radicals exceeds the scavenging capacity of the cell's endogenous systems, the excess free radicals seek stability through electron pairing with biological macromolecules of healthy cells such as proteins, lipids, and DNA. The pairing of the free radicals with biomolecules can eventually result in the induction of lipid peroxidation which leads to cancer, atherosclerosis, cardiovascular diseases, ageing, and inflammatory diseases $[2,4]$. Prolonged oxidative stress can result in permanent damage to vital body organs, which could eventually lead to chronic disorders such as heart diseases, diabetes, cirrhosis, malaria, neurodegenerative diseases, AIDS, cancer, and premature aging $[3,5]$. It has been 
noted that about $95 \%$ of the pathologies observed in people above 35 years of age are associated with production and accumulation of free radicals [6].

Nitric oxide (NO) and reactive nitrogen species (RNS) are free radicals that are derived from the interaction of $\mathrm{NO}$ with oxygen or reactive oxygen species [7]. Nitric oxide is classified as a free radical because of its unpaired electron and displays important reactivity with certain types of proteins and other free radicals such as superoxide [8]. NO is synthesized by three isoforms of the enzyme nitric oxide synthase (NOS), endothelial NOS, neuronal NOS, and inducible NOS (iNOS). Nitric oxide (NO) is generated from amino acid L-arginine by the enzymes in the vascular endothelial cells, certain neuronal cells, and phagocytes [3]. Low concentrations of $\mathrm{NO}$ are sufficient in most cases to effect the physiological functions of the radical. NO is a diffusible free radical that plays many roles as an effectors molecule in diverse biological systems including neuronal messenger, vasodilatation, and antimicrobial and antitumor activities [9]. Chronic exposure to nitric oxide radical is associated with various carcinomas and inflammatory conditions including juvenile diabetes, multiple sclerosis, arthritis, and ulcerative colitis. The toxicity of NO increases greatly when it reacts with the superoxide radical, forming the highly reactive peroxynitrite anion $\left(\mathrm{ONOO}^{-}\right)$[8]. Nitric oxide has been shown to be directly scavenged by flavonoids [10].

Natural antioxidants are considered to be safe and bioactive [11]. The antioxidants from natural sources are the only alternative to synthetic antioxidants in counteracting the free radicals associated disease [3]. The antioxidant activities of phenolic compounds are mainly due to the redox properties, which allow them to act as reducing agents, hydrogen donors, and singlet oxygen quenchers, in addition to their metal chelating potential. The antioxidant activity of phenolics plays an important role in the adsorption or neutralization of free radicals [9]. In vitro quenching of NO radical is one of the methods that can be used to determine antioxidant activity [3]. The procedure is based on the principle that sodium nitroprusside in aqueous solution at physiological $\mathrm{pH}$ spontaneously generates nitric oxide which interacts with oxygen to produce nitrite ions that can be estimated using Griess reagent. Scavengers of nitric oxide compete with oxygen, leading to reduced production of nitrite ions [12].

In recent years, various species of plants have been used in preparation of drugs and are consumed as food due to their antioxidant activities [13]. The extracts of medicinal plants and natural products have become a great source of antioxidant and antiageing properties [14]. Recently, much attention has been directed towards the development of ethnomedicines with strong antioxidant properties but with low cytotoxicity [15]. Therefore, antioxidants with free radical scavenging activities of medicinal plants may have great relevance in the prevention of diseases and in therapeutic properties [16]. Plants, rich in their phytochemical compounds, are good sources of antioxidants and radical scavengers [5]. Combretum platypetalum has been used traditionally for swelling caused by mumps, pneumonia, abdominal pains, diarrhoea, antiemetic, dysmenorrhoea, infertility in women, earache, epistaxis, and haemoptysis [17]. Parinari species, such as $P$. curatellifolia and $P$. excelsa, are traditionally used in Africa as a remedy for dysentery, epilepsy, malaria, toothache, and venereal diseases [18]. The leaves of $P$. curatellifolia are indicated to treat stomach aches in Southern Uganda [19]. Combretum zeyheri has been used traditionally to treat conditions such as toothache, cough, scorpion bite, bloody diarrhoea, arrest of menstrual flow, and abdominal pain.

Modern pharmaceuticals and nutriceuticals are currently out of reach of a large proportion of the human population in developing countries [20]. This necessitates the use of other sources of human knowledge to provide common health benefits. Thus, herbal medicines are now regarded as important but underutilized tool against the disease [21]. The widespread use of Combretum species and Parinari species in indigenous medicine for many different ailments exhibited by several species and the need for effective antioxidant agents justify the further investigation of the antioxidant activity of Combretum species and Parinari species that are found in Zimbabwe. The main objective of the study was to determine the antioxidant activity of C. zeyheri, C. platypetalum, and $P$. curatellifolia leaf extracts and $P$. curatellifolia phytoconstituents by nitrite radical scavenging assay.

\section{Materials and Methods}

2.1. Materials. All chemicals used were purchased from Sigma-Aldrich chemical company (Darmstadt, Germany). These were ethanol, methanol, N-butanol, ammonia, aluminium chloride, potassium acetate, quercetin, gallic acid (GA), sulphanilamide, naphthalene diamine dihydrochloride, phosphoric acid, sodium nitroprusside (SNP), $\mathrm{KH}_{2} \mathrm{PO}_{4}$ (monobasic anhydrous), $\mathrm{Na}_{2} \mathrm{HPO}_{4}$ (dibasic anhydrous), sodium chloride $(\mathrm{NaCl})$, and potassium chloride $(\mathrm{KCl})$.

\subsection{Collection and Preparation of Plant Material. Leaves of} Combretum zeyheri, Combretum platypetalum, and Parinari curatellifolia were collected from Norton, Mashonaland Central, Zimbabwe. The plants were classified by Mr. Christopher Chapano, a taxonomist at the National Herbarium and Botanic Gardens (Harare, Zimbabwe). The plant leaves were dried in a Labcon orbital incubator (Labotech Co., Cape Town, South Africa). The plants were stored in the Biomolecular Laboratory at the Department of Biochemistry, University of Zimbabwe.

2.3. Preparation of Extracts. For the ethanol extracts, dried leaves of the plant species were ground in a two-speed blender (Cole Palmer Instrument Co., USA) and the samples were extracted with ethanol on an orbital shaker (Bibby Scientific Limited, Staffordshire, UK) using a 4:1 solvent to dry weight ratio for $10-15$ mins. The extract was filtered through a Whatman filter paper and the filtrate was decanted into preweighed labelled containers. The filtrate was concentrated under a fan and then weighed and percentage yield was calculated. For the water extracts approximately $1 \mathrm{~g}$ of dry fine powder was suspended in $10 \mathrm{~mL}$ distilled water. The extract solution was stirred magnetically for $24 \mathrm{hrs}$ at room temperature on a magnetic stirrer (Minor-2 Voss Instruments 
Ltd., Malden, Essex). The extracts were then filtered using a Whatman number 1 filter paper. The filtrate was concentrated to dryness in a Labcon Incubator (Labotec Co., Cape Town, South Africa) to obtain the crude extracts.

2.4. Isolation of Phytoconstituents. The phytoconstituents were isolated from Parinari curatellifolia [22]. Alkaloids were isolated by mixing $1 \mathrm{~g}$ of powdered sample with $1 \mathrm{~mL}$ of $10 \%(\mathrm{v} / \mathrm{v})$ ammonia solution and extracted with $5 \mathrm{~mL}$ ethanol for 10 mins on a water bath at $40^{\circ} \mathrm{C}$. The extracted solution was then filtered through Whatman filter paper No. 1 and the filtrate was concentrated using air drying under a fan. Isolation of flavonoids was achieved by heating $1 \mathrm{~g}$ of powdered sample with $5 \mathrm{~mL}$ methanol on a water bath at $40^{\circ} \mathrm{C}$ for $10 \mathrm{mins}$. The filtrate was then concentrated to $1 / 4$ th of its original volume and was dried under a fan to a powdered extract. For saponins, $1 \mathrm{~g}$ of powdered sample was extracted with $5 \mathrm{~mL}$ methanol by heating on a water bath at $40^{\circ} \mathrm{C}$ for 10 minutes. The extract was filtered and evaporated to $1 \mathrm{~mL}$, mixed with $0.5 \mathrm{~mL}$ water, and then extracted thrice with $3 \mathrm{~mL}$-butanol. The solution was allowed to separate into phases. The aqueous phase was decanted and the nbutanol phase was evaporated and concentrated under a fan. Aluminium chloride colorimetric method was used for flavonoid determination [23]. Each plant extract $(0.5 \mathrm{~mL})$ of $1,2,4 \mathrm{mg} / \mathrm{mL}$ methanol was mixed with $1.5 \mathrm{~mL}$ of methanol, $0.1 \mathrm{~mL}$ of $10 \%$ aluminium chloride, $0.1 \mathrm{~mL}$ of $1 \mathrm{M}$ potassium acetate, and $2.8 \mathrm{~mL}$ of distilled water. It remained at room temperature for $30 \mathrm{mins}$. A volume of $150 \mu \mathrm{L}$ was pipetted in a 96-well plate and the absorbance of the reaction mixture was measured at $415 \mathrm{~nm}$ in a SpectraMax Plus microplate reader (Molecular Devices, CA, USA). The calibration curve was prepared by preparing quercetin solutions at concentrations of 6 to $100 \mathrm{mg} / \mathrm{mL}$ in methanol. The quantity of flavonoids was interpolated from the calibration curve of quercetin using GraphPad Instat software (GraphPad Prism Inc., San Diego, CA, USA).

2.5. Nitric Oxide Radical Scavenging Assay. The assay is the nitric oxide radical scavenging assay [24]. The extracts were prepared from a $10 \mathrm{mg} / \mathrm{mL}$ ethanol crude extract. These were then serially diluted with distilled water to make concentrations from $100-1000 \mu \mathrm{g} / \mathrm{mL}$ of the three plants and the standard gallic acid. These were stored at $4^{\circ} \mathrm{C}$ for later use. Griess reagent was prepared by mixing equal amounts of $1 \%$ sulphanilamide in $2.5 \%$ phosphoric acid and $0.1 \%$ naphthylethylene diamine dihydrochloride in $2.5 \%$ phosphoric acid immediately before use. A volume of $0.5 \mathrm{~mL}$ of $10 \mathrm{mM}$ sodium nitroprusside in phosphate buffered saline was mixed with $1 \mathrm{~mL}$ of the different concentrations of the ethanol extracts $(100-1000 \mu \mathrm{g} / \mathrm{mL})$ and incubated at $25^{\circ} \mathrm{C}$ for 180 mins. The extract was mixed with an equal volume of freshly prepared Griess reagent. Control samples without the extracts but with an equal volume of buffer were prepared in a similar manner as was done for the test samples. The colour tubes contained ethanol extracts at the same concentrations with no sodium nitroprusside. A volume of $150 \mu \mathrm{L}$ of the reaction mixture was transferred to a 96-well plate. The absorbance was measured at $546 \mathrm{~nm}$ using a SpectraMax Plus UV-Vis microplate reader (Molecular Devices, GA, USA). Gallic acid was used as the positive control. The percentage inhibition of the extract and standard was calculated and recorded. The percentage nitrite radical scavenging activity of the ethanol extracts and gallic acid were calculated using the following formula:

percentage nitrite radical scavenging activity:

$$
\text { nitric oxide scavenged }(\%)=\frac{A_{\text {control }}-A_{\text {test }}}{A_{\text {control }}} \times 100 \text {, }
$$

where $A_{\text {control }}=$ absorbance of control sample and $A_{\text {test }}=$ absorbance in the presence of the samples of extracts or standards.

2.6. Statistical Analysis. Data analyses were performed using GraphPad Instat software (GraphPad Prism Inc., San Diego, CA, USA). Levels of significance were determined using ANOVA using the Dunnet post test where all columns of treatments were compared to the control. All data were expressed as mean \pm standard deviation. $P \leq 0.05$ values or less were considered to indicate statistically significant difference.

\section{Results}

3.1. Quantification of Flavonoids Isolated from P. curatellifolia Dried Leaves. The total flavonoid content for methanolic extracts of P. curatellifolia was found to be $0.4 \pm 0.05142 \mathrm{mg} / \mathrm{g}$ of quercetin equivalent.

\subsection{Nitrite Radical Scavenging Assay}

3.2.1. Ethanol Extracts of C. zeyheri, C. platypetalum, and P. curatellifolia. Nitrite radical scavenging assay was carried out on the ethanol extracts of C. zeyheri, C. platypetalum, and $P$. curatellifolia dried leaves from a concentration of 100 to $1000 \mu \mathrm{g} / \mathrm{mL}$. Percentage free radical scavenging was plotted against concentration of the extracts as shown in Figure 1. The plants exhibited antioxidant activity through competing with oxygen to scavenge for the nitrite radical which was generated from SNP at physiological $\mathrm{pH}$ in an aqueous environment. The antioxidant activity increased with an increase in concentration of the extracts reaching a plateau. Increasing the concentration of the extracts did not result in an increase in the nitrite radical scavenging activity. The maximum free radical scavenging activity and potency were interpolated from Figure 1 to give results as shown in Table 1. P. curatellifolia ethanol extract was the most potent as it removed the nitrite radical at a lower concentration as compared to the other plant extracts. $P$. curatellifolia had a maximal scavenging activity at $103 \mu \mathrm{g} / \mathrm{mL}$ followed by C. platypetalum which was at $158 \mu \mathrm{g} / \mathrm{mL}$ and C. zeyheri at $188 \mu \mathrm{g} / \mathrm{mL}$.

3.2.2. Water Extracts of C. zeyheri, C. platypetalum, and P. curatellifolia. The nitrite radical scavenging assay was carried out on the water extracts from a concentration range of 100 to 


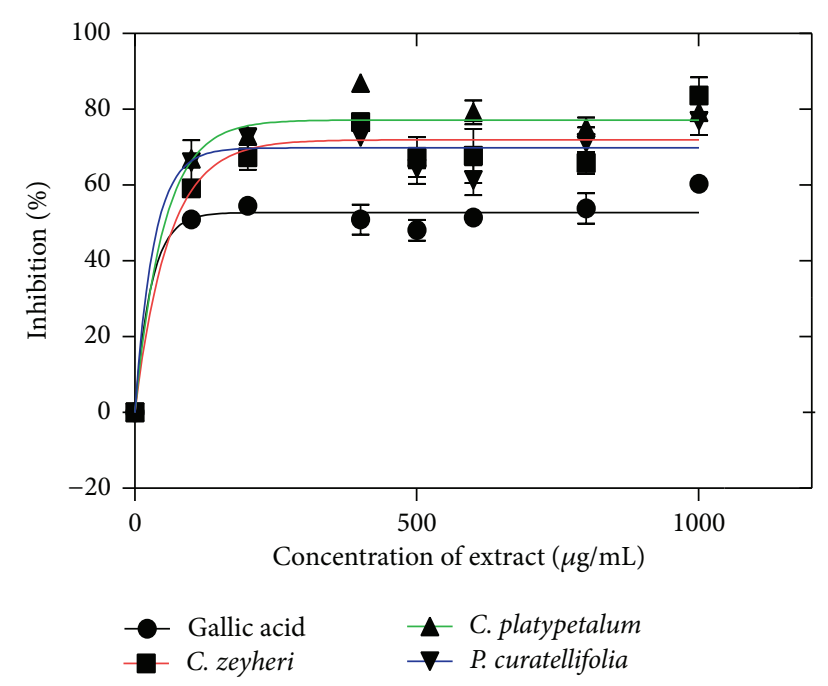

FIGURE 1: Nitric oxide scavenging activity of ethanol extracts from dried leaves of C. zeyheri, C. platypetalum, and P. curatellifolia.

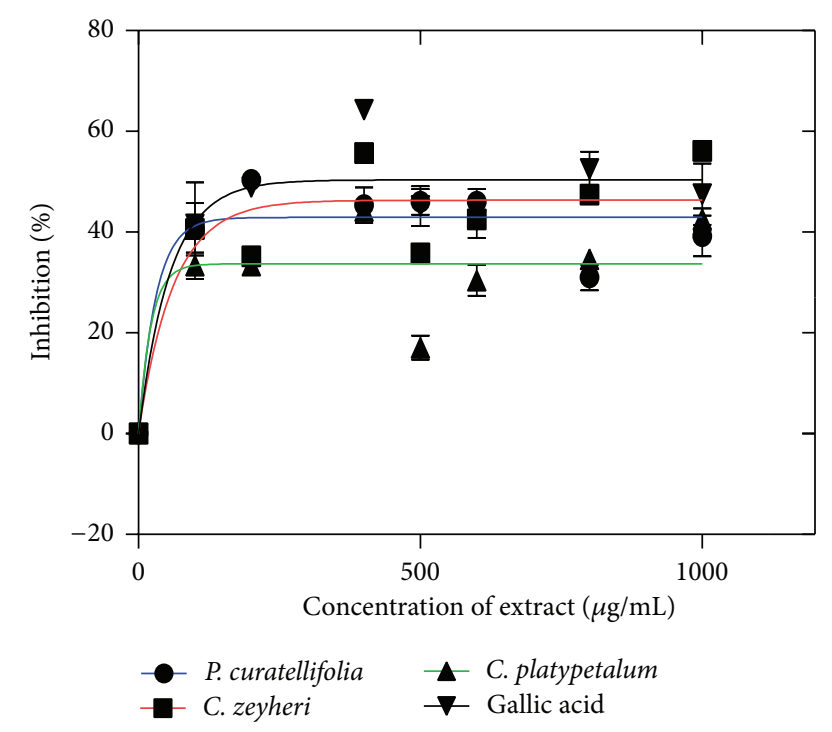

FIgURE 2: Nitric oxide scavenging activity of water extracts from leaves of C. zeyheri, C. platypetalum, and P. curatellifolia.

$1000 \mu \mathrm{g} / \mathrm{mL}$. The percentage radical scavenging of the nitrite radical by the water extracts is shown in Figure 2. The water extracts exhibited less free radical scavenging capacity than the ethanol extracts. The trend of antioxidant activity was the same for both ethanol and water extracts with C. platypetalum showing the highest capability of quenching the NO radical followed by $C$. zeyheri and $P$. curatellifolia, respectively, as the results in Table 1 indicate. The ethanol extracts results were used to determine potency and maximum percentage scavenging of the plants since they exhibited the greatest scavenging activity as compared to the water extracts. The potency of the extracts was interpolated from the graph in Figure 1. The summary of the results is shown below in Table 1 .
TABLE 1: Nitrite radical scavenging activity of gallic acid and Combretum zeyheri, Combretum platypetalum, and Parinari curatellifolia extracts.

\begin{tabular}{lccc}
\hline Plant & $\begin{array}{c}\text { Ethanol extracts } \\
\mu \mathrm{g} / \mathrm{mL}\end{array}$ & $\begin{array}{c}\text { Water extracts } \\
\mu \mathrm{g} / \mathrm{mL}\end{array}$ & $\begin{array}{c}\text { Nitric oxide } \\
\text { scavenged \% }\end{array}$ \\
\hline C. zeyheri & 188 & 198 & 72.5 \\
C. platypetalum & 158 & 97.5 & 77.5 \\
P. curatellifolia & 103 & 92.5 & 70 \\
Gallic acid & 87.5 & 173 & 53.5 \\
\hline
\end{tabular}

3.2.3. Isolated Phytoconstituents from P. curatellifolia. The nitrite radical assay was carried out on the isolated phytochemicals from the most potent plant $P$. curatellifolia. The assay was done on saponins, alkaloids, and flavonoids from a concentration range of 100 to $1000 \mu \mathrm{g} / \mathrm{mL}$. The results were analysed using GraphPad Prism 5 software and these are shown in Figure 3 and the values were used to determine potency and the greatest percentage radical scavenging of the phytochemicals. The results are shown in Table 2 . The results showed that the saponins were the most potent followed by flavonoids and lastly alkaloids. The maximal scavenging activity was shown by alkaloids, then saponins, and lastly flavonoids.

\section{Discussion}

It is widely recognized that many of today's diseases are due to the oxidative stress that results from an imbalance between formation of ROS/RNS and their neutralization when endogenous antioxidant mechanisms are unable to quench the free radicals [25]. The free radicals are known to be scavenged by synthetic antioxidants, but due to their adverse side effects leading to carcinogenicity, search for effective and natural antioxidants has become crucial [26]. Natural antioxidants are believed to be safer and bioactive [12].

Nitric oxide (NO) is generated from amino acid Larginine by vascular endothelial cells, phagocytes, and certain cells of the brain. Nitric oxide is classified as a free radical because of its unpaired electron and displays important reactivity with certain types of proteins and other free radicals. The toxicity of NO becomes adverse when it reacts with superoxide radical, forming a highly reactive peroxynitrite anion $\left(\mathrm{ONOO}^{-}\right)$[3].

The antioxidants from natural sources could be the alternative to synthetic antioxidants in counteracting oxidative stress associated diseases. A great number of naturally occurring substances have been recognized to have antioxidant abilities and various in vitro methods have been used to assess their free radical scavenging and antioxidant activity. Therefore, in the present study, C. zeyheri, C. platypetalum, and $P$. curatellifolia at different concentrations were assessed for their nitrite free radical scavenging activity in an in vitro model. The nitric oxide generated from sodium nitroprusside reacts with oxygen to form nitrite. The nitrite ions diazotize with sulphanilamide acid and couple with naphthyl ethylenediamine, forming pink colour, which was measured at $546 \mathrm{~nm}$ 


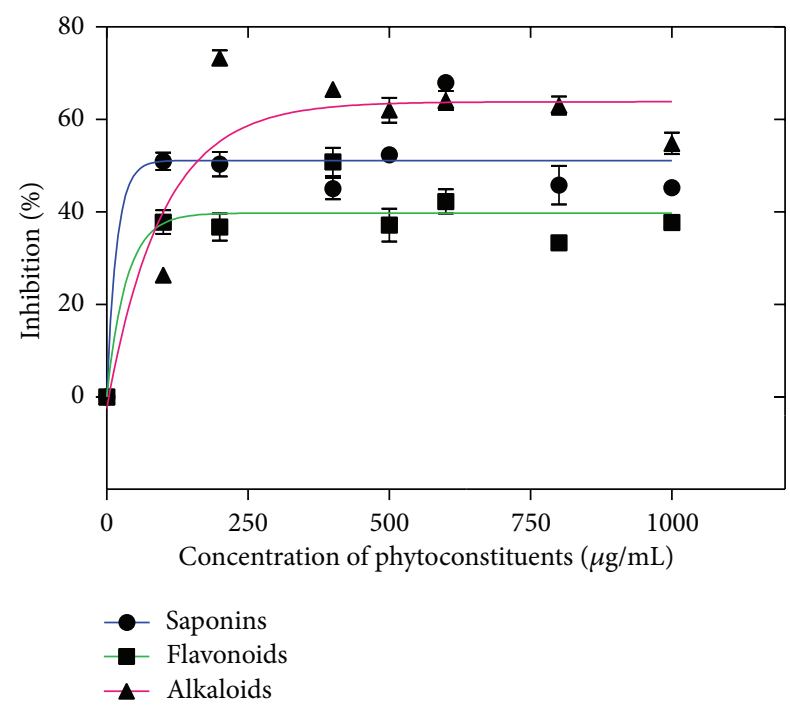

FIGURE 3: Nitric oxide scavenging activity of the isolated phytoconstituents extracts from leaves of $P$. curatellifolia.

TABle 2: Nitrite radical activity of Parinari curatellifolia phytoconstituents.

\begin{tabular}{lcc}
\hline Phytoconstituents & Potency $(\mu \mathrm{g} / \mathrm{mL})$ & Nitric oxide scavenged \% \\
\hline Alkaloids & 197 & 64 \\
Saponins & 62 & 52 \\
Flavonoids & 78 & 41 \\
\hline
\end{tabular}

[24]. As antioxidants donate protons to the nitrite radical, the absorbance is decreased. The decrease in absorbance was used to measure the extent of nitrite radical scavenging [27].

It was observed that all the extracts both ethanol and water scavenged nitrite radical in a dose dependent manner and reached a plateau in which a further increase in the concentration of the extracts did not result in an increase in the quenching of the nitrite radical. Hence, C. zeyheri, C. platypetalum, and P. curatellifolia leaf extracts have antioxidant activity, particularly when compared to the positive control, gallic acid. Figures 1 and 2 illustrate that there is a significant decrease in the NO radical due to the scavenging ability of extracts and gallic acid. Based on the results, the ethanol extracts of the three plants were found to be the more effective nitric oxide scavengers than the water extracts. The activity of the ethanol extracts could be attributed to the components such as phenolic compounds that are isolated by each solvent. Polyphenols are considered one of the major antioxidant components in plant extracts [28]. Ethanol extracts are thought to contain more polyphenols compared to aqueous extracts as ethanol is more efficient at penetrating the cellular membrane to extract the intracellular ingredients from the plant material resulting in more efficient extraction of polyphenols [29]. The decrease in activity of the aqueous extract could be ascribed to polyphenol oxidase, which degrades polyphenols in water extracts but is inactive in methanol and ethanol [29]. Previous studies by Masoko and Eloff have shown that ethanol extracted the highest quantity of antioxidant compounds based on the DPPH-TLC analysis they conducted [2].

When comparing the three extracts with standard gallic acid the ethanol extract of P. curatellifolia was the most potent nitric radical scavenger than that of the other two extracts C. zeyheri and C. platypetalum. The values of potency as shown in Table 1 are as follows: $P$. curatellifolia $>$ C. platypetalum > C. zeyheri. The values are $103 \mu \mathrm{g} / \mathrm{mL}, 158 \mu \mathrm{g} / \mathrm{mL}$, and $188 \mu \mathrm{g} / \mathrm{mL}$, respectively. The same trend was observed with the water extracts and the potency results are $92.5 \mu \mathrm{g} / \mathrm{mL}$, $97.5 \mu \mathrm{g} / \mathrm{mL}$, and $198 \mu \mathrm{g} / \mathrm{mL}$, respectively. The ethanol extracts inhibited the nitrite radical more than the standard gallic acid and the water extracts inhibited the nitrite radical less than the gallic acid. Although the ethanol extracts scavenged the nitrite radical at higher concentrations, gallic acid was more potent as shown by the value which was $87.5 \mu \mathrm{g} / \mathrm{mL}$; this showed that it inhibited the nitrite radical at lower concentrations.

Chronic exposure to nitric oxide radical is associated with various carcinomas and inflammatory conditions including juvenile diabetes, multiple sclerosis, arthritis, and ulcerative colitis [30]. In view of that the study has shown that these three plant extracts, both ethanol and water, can be used as sources of antioxidants. A study by Masoko and Eloff showed that the leaves of the Combretaceae family are known for their pharmacological activity and that various solvents extracted antioxidant compounds from the leaves of the plants belonging to members of the Combretaceae family [2].

After discovering that $P$. curatellifolia was more potent, phytoconstituents were isolated from it. The phytoconstituents saponins, alkaloids, and flavonoids were isolated from $P$. curatellifolia by different methods and their nitrite radical scavenging activity was determined. Saponins were the most potent followed by flavonoids and then alkaloids at concentration values of $61.6 \mu \mathrm{g} / \mathrm{mL}, 77.5 \mu \mathrm{g} / \mathrm{mL}$, and $197 \mu \mathrm{g} / \mathrm{mL}$, respectively.

Flavonoids are one of the most diverse and widespread groups of natural compounds and are probably the most important natural phenolics. These compounds possess a broad spectrum of chemical and biological activities including radical scavenging properties [29]. The assumption that other phytochemicals had been extracted was made; hence there was a need to quantify the flavonoids that were present in the crude extract of $P$. curatellifolia. The total flavonoid content of the methanolic extract of $P$. curatellifolia dried leaves was $0.4 \pm 0.05142 \mathrm{mg} / \mathrm{mL}$ quercetin equivalent. A study by Ogunbolude et al. showed that the flavonoid content of $P$. curatellifolia seeds was $1.57 \pm 00.17 \mathrm{mg} / \mathrm{g}$ quercetin equivalent [31]. The difference could be as a result of the differences in the plant part that was used, seeds as compared to the leaves. The difference in geographical location in the same species of a plant could also explain the differences.

P. curatellifolia is thought to utilize various antioxidative mechanisms which include free radical scavenging, reduction, and deactivation by chelation of transition metals involved in the initiation of free radical induced macromolecular damage. Our results indicate that $P$. curatellifolia is a potent scavenger of the nitrite radical. The phytoconstituents isolated from P. curatellifolia have all been shown in several 
studies to have antioxidant activity as well. Phenols and polyphenolic compounds, such as flavonoids, are widely found in food products derived from plant sources, and they have been shown to possess significant antioxidant activities [32]. Preliminary phytochemical screening on P. curatellifolia indicated the presence of antioxidant compounds such as polyphenols [33]. The ethanolic extracts of the seeds contained polyphenols, flavonoids, vitamin $\mathrm{C}$, and nonprotein thiols such as glutathione. Glutathione and vitamin $\mathrm{C}$ are well-known antioxidants that are found in plants and provide exogenous antioxidant mechanisms to cells. NO has been found to be directly scavenged by flavonoids [11]. The presence of flavonoids and saponins could explain why $P$. curatellifolia was more potent at quenching the NO radical than the other plants C. zeyheri and C. platypetalum in this study.

\section{Conclusion}

In conclusion, the results obtained in the present study indicated that ethanol and water extracts of C. zeyheri, C. platypetalum, and P. curatellifolia scavenged the nitrite radical showing that they are potent antioxidants. Hence, these plant extracts can be used as natural sources of antioxidants as they could have great importance as therapeutic agents in preventing or slowing the progress of aging and age associated oxidative stress related degenerative diseases. They also have potential application in industry as natural antioxidants that could be used as food additives to prevent food deterioration as synthetic antioxidants that are available are associated with a lot of side effects.

$\begin{array}{ll}\text { Abbreviations } \\ \text { BHA: } & \text { Butylated hydroxyl anisole } \\ \text { BHT: } & \text { Butylated hydroxyl toluene } \\ \text { DPPH-TLC: } & \text { 2, 2-Diphenyl-1-picryl hydrazyl-thin layer } \\ & \text { chromatograph } \\ \text { GA: } & \text { Gallic acid } \\ \text { GPx: } & \text { Glutathione peroxidase } \\ \text { GSH: } & \text { Glutathione } \\ \text { iNOS: } & \text { Nitric oxide synthase (iNOS) } \\ \text { NADH: } & \text { Nicotinamide adenine dinucleotide } \\ & \text { hydrogen } \\ \text { NO: } & \text { Nitric oxide } \\ \text { PG: } & \text { Propyl gallate } \\ \text { ROS: } & \text { Reactive oxygen species } \\ \text { RNS: } & \text { Reactive nitrogen species } \\ \text { SOD: } & \text { Superoxide dismutase } \\ \text { SNP: } & \text { Sodium nitroprusside. }\end{array}$

\section{Conflict of Interests}

The authors report no conflict of interests. The authors alone are responsible for the content and writing of the paper.

\section{Acknowledgments}

This study was sponsored by the International Foundation in Sciences (IFS), Stockholm, Sweden, Grant no. F/3413-03F. Support from the International Program in the Chemical Sciences (IPICS: ZIM01), Uppsala University, Uppsala, Sweden, and the University of Zimbabwe Research Board (Harare, Zimbabwe) is also acknowledged. The authors would like to thank Ms. Batanai Moyo for the final proofreading of the paper.

\section{References}

[1] C. L. Chang, C. S. Lin, and G. H. Lai, "Phytochemical characteristics, free radical scavenging activities, and neuroprotection of five medicinal plant extracts," Evidence-based Complementary and Alternative Medicine, vol. 2012, Article ID 984295, 8 pages, 2012.

[2] P. Masoko and J. N. Eloff, "Screening of twenty-four South African Combretum and six Terminalia species for antioxidant activites," African Journal of Traditional, Complementary and Alternative Medicines, vol. 4, no. 2, pp. 231-239, 2007.

[3] D. M. Nagmoti, D. K. Khatri, P. R. Juvekar, and A. R. Juvekar, "Antioxidant activity and free radical-scavenging potential of Pithecellobium dulce Benth seed extracts," Free Radical and Antioxidants, vol. 2, no. 2, pp. 37-43, 2011.

[4] Z. Hodzic, H. Pasalic, A. Memisevic, M. Srabovic, M. Saletovic, and M. Poljakovic, "The influence of total phenols content on antioxidant capacity in the whole grain extracts," European Journal of Scientific Research, vol. 28, no. 3, pp. 471-477, 2009.

[5] A. Agarwal, A. Aponte-Mellado, B. J. Premkumar, A. Shaman, and S. Gupta, "The effects of oxidative stress on female reproduction: a review," Reproductive Biology and Endocrinology, vol. 10, article 49, 2012.

[6] G. Gunalan, N. Myla, and R. Balabhaskar, "In vitro antioxidant analysis of selected coffee bean varieties," Journal of Chemical and Pharmaceutical Research, vol. 4, no. 4, pp. 2126-2132, 2012.

[7] P.-J. Tsai, T.-H. Tsai, C.-H. Yu, and S.-C. Ho, "Evaluation of NOsuppressing activity of several Mediterranean culinary spices," Food and Chemical Toxicology, vol. 45, no. 3, pp. 440-447, 2007.

[8] O. U. Amaeze, G. A. Ayoola, M. O. Sofidiya, A. A. AdepojuBello, A. O. Adegoke, and H. A. B. Coker, "Evaluation of antioxidant activity of Tetracarpidium conophorum (Müll. Arg) Hutch \& Dalziel leaves," Oxidative Medicine and Cellular Longevity, vol. 2011, Article ID 976701, 7 pages, 2011.

[9] H. V. Bhaskar and N. Balakrishnan, "In vitro antioxidant property of laticiferous plant species from Western Ghats Tamilnadu, India," International Journal of Health Research, vol. 2, no. 2, pp. 163-170, 2009.

[10] P. Lakhanpal and D. K. Rai, "Quercetin: a versatile flavonoid," Internet Journal of Medical Update, vol. 2, no. 2, pp. 22-37, 2007.

[11] V. R. Patel, P. R. Patel, and S. S. Kaja, "Antioxidant activity of some selected medicinal plants in Western region of India," Advances in Biological Research, vol. 4, no. 1, pp. 23-26, 2010.

[12] M. A. Ebrahimzadeh, S. M. Nabavi, S. F. Nabavi, F. Bahramian, and A. R. Bekhradnia, "Antioxidant and free radical scavenging activity of $H$. officinalis $L$. var. angustifolius, V. odorata, B. hyrcana and C. speciosum," Pakistan Journal of Pharmaceutical Sciences, vol. 23, no. 1, pp. 29-34, 2010. 
[13] D. K. Sahoo and A. Roy, "Compromised rat testicular antioxidant defence system by hypothyroidism before puberty," International Journal of Endocrinology, vol. 2012, Article ID 637825, 11 pages, 2012.

[14] Y. Sumazian, A. Syahida, M. Hakiman, and M. Maziah, "Antioxidant activities, flavonoids, ascorbic acid and phenolic contents of Malaysian vegetables," Journal of Medicinal Plant Research, vol. 4, no. 10, pp. 881-890, 2010.

[15] B. Hazra, S. Biswas, and N. Mandal, "Antioxidant and free radical scavenging activity of Spondias pinnata," BMC Complementary and Alternative Medicine, vol. 8, article 63, 2008.

[16] M. R. Udhayasankar, U. Danya, and K. Arumugasamy, "Phytochemistry and Free radical scavenging activity of Wattakaka volubilis (Linn. f.) Benth ex. Hook f. (Asclepiadaceae)-a rare and threatened medicinal plant," International Journal of PharmTech Research, vol. 4, no. 3, pp. 1025-1032, 2012.

[17] C. B. Rogers and L. Verotta, "Chemistry and biological properties of the African Combretaceae," in Chemistry, Biological and Pharmacological Properties of African Medicinal Plants, $\mathrm{K}$. Hostettman, F. Chinyanganga, M. Maillard, and J. L. Wolfender, Eds., University of Zimbabwe Publications, 1996.

[18] A. C. U. Uys, S. F. Malan, S. Van Dyk, and R. L. Van Zyl, "Antimalarial compounds from Parinari capensis," Bioorganic and Medicinal Chemistry Letters, vol. 12, no. 16, pp. 2167-2169, 2002.

[19] P. Ssegawa and J. M. Kasenene, "Medicinal plant diversity and uses in the Sango bay area, Southern Uganda," Journal of Ethnopharmacology, vol. 113, no. 3, pp. 521-540, 2007.

[20] R. K. Gupta, A. K. Patel, R. Kumari et al., "Interactions between oxidative stress, lipid profile and antioxidants in breast cancer: a case control study," Asian Pacific Journal of Cancer Prevention, vol. 13, no. 12, pp. 6295-6298, 2012.

[21] R. Bajpai, N. Jain, and A. K. Pathak, "Standardization of ethanolic extract of Cucurbita maxima seed," Journal of Applied Pharmaceutical Science, vol. 2, no. 8, pp. 92-95, 2012.

[22] J. B. Harborne, Phytochemical Methods-A Guide to Modern Techniques of Plant Analysis, Springer, New Delhi, India, 3rd edition, 2005.

[23] N. F. Omar, S. A. Hassan, U. K. Yusoff, N. A. P. Abdullah, P. E. M. Wahab, and U. R. Sinniah, "Phenolics, flavonoids, antioxidant activity and cyanogenic glycosides of organic and mineral-base fertilized cassava tubers," Molecules, vol. 17, no. 3, pp. 2378-2387, 2012.

[24] B. N. Panda, A. B. Raj, N. R. Shrivastava, and A. R. Prathani, "The evaluation of nitric oxide scavenging activity of Acalypha indica Linn Root," Asian Journal Research Chemistry, vol. 2, no. 2, pp. 148-150, 2009.

[25] A. S. V. C. Rao, S. G. Reddy, P. P. Babu, and A. R. Reddy, "The antioxidant and antiproliferative activities of methanolic extracts from Njavara rice bran," BMC Complementary and Alternative Medicine, vol. 10, article 4, 2010.

[26] A. A. Adedapo, F. O. Jimoh, S. Koduru, P. J. Masika, and A. J. Afolayan, "Assessment of the medicinal potentials of the methanol extracts of the leaves and stems of Buddleja saligna," BMC Complementary and Alternative Medicine, vol. 9, article 21, 2009.

[27] A. Turkoglu, M. E. Duru, N. Mercan, I. Kivrak, and K. Gezer, "Antioxidant and antimicrobial activities of Laetiporus sulphureus (Bull.) Murrill," Food Chemistry, vol. 101, no. 1, pp. 267-273, 2007.
[28] W. Zheng and S. Y. Wang, "Antioxidant activity and phenolic compounds in selected herbs," Journal of Agricultural and Food Chemistry, vol. 49, no. 11, pp. 5165-5175, 2001.

[29] M. Valko, H. Morris, and M. T. D. Cronin, "Metals, toxicity and oxidative stress," Current Medicinal Chemistry, vol. 12, no. 10, pp. 1161-1208, 2005.

[30] R. E. Huie and S. Padmaja, "The reaction of no with superoxide," Free Radical Research Communications, vol. 18, no. 4, pp. 195199, 1993

[31] Y. Ogunbolude, M. A. Ajayi, T. M. Ajagbawa, A. P. Igbakin, J. B. T. Rocha, and I. J. Kade, "Ethanolic extracts of seeds of Parinari curatellifolia exhibit potent antioxidant properties: a possible mechanism of its antidiabetic action," Journal of Pharmacognosy and Phototherapy, vol. 1, no. 6, pp. 67-75, 2009.

[32] S. M. Nabavi, M. A. Ebrahimzadeh, S. F. Nabavi, M. Fazelian, and B. Eslami, "In vitro antioxidant and free radical scavenging activity of Diospyros lotus and Pyrus boissieriana growing in Iran," Pharmacognosy Magazine, vol. 4, no. 18, pp. 122-126, 2009.

[33] S. O. Ogbonnia, G. O. Mbaka, E. N. Anyika et al., "Evaluation of anti-diabetics and cardiovascular effects of Parinari curatellifolia seed extract and Anthoclista vogelli root extract individually and combined on postprandial and alloxan-induced diabetic albino rats," British Journal of Medicine \& Medical Research, vol. 1, no. 3, pp. 146-162, 2011. 

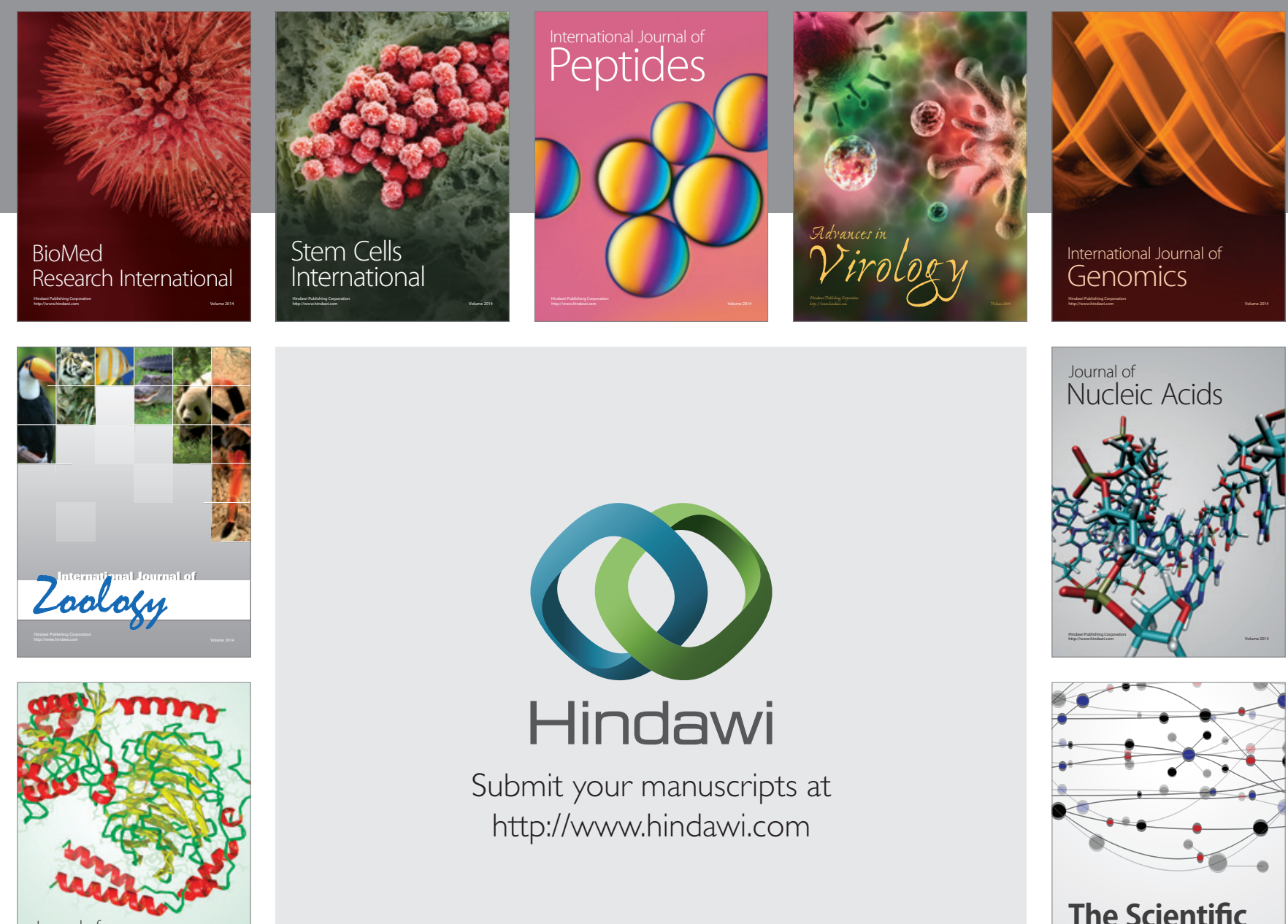

Submit your manuscripts at

http://www.hindawi.com

Journal of
Signal Transduction
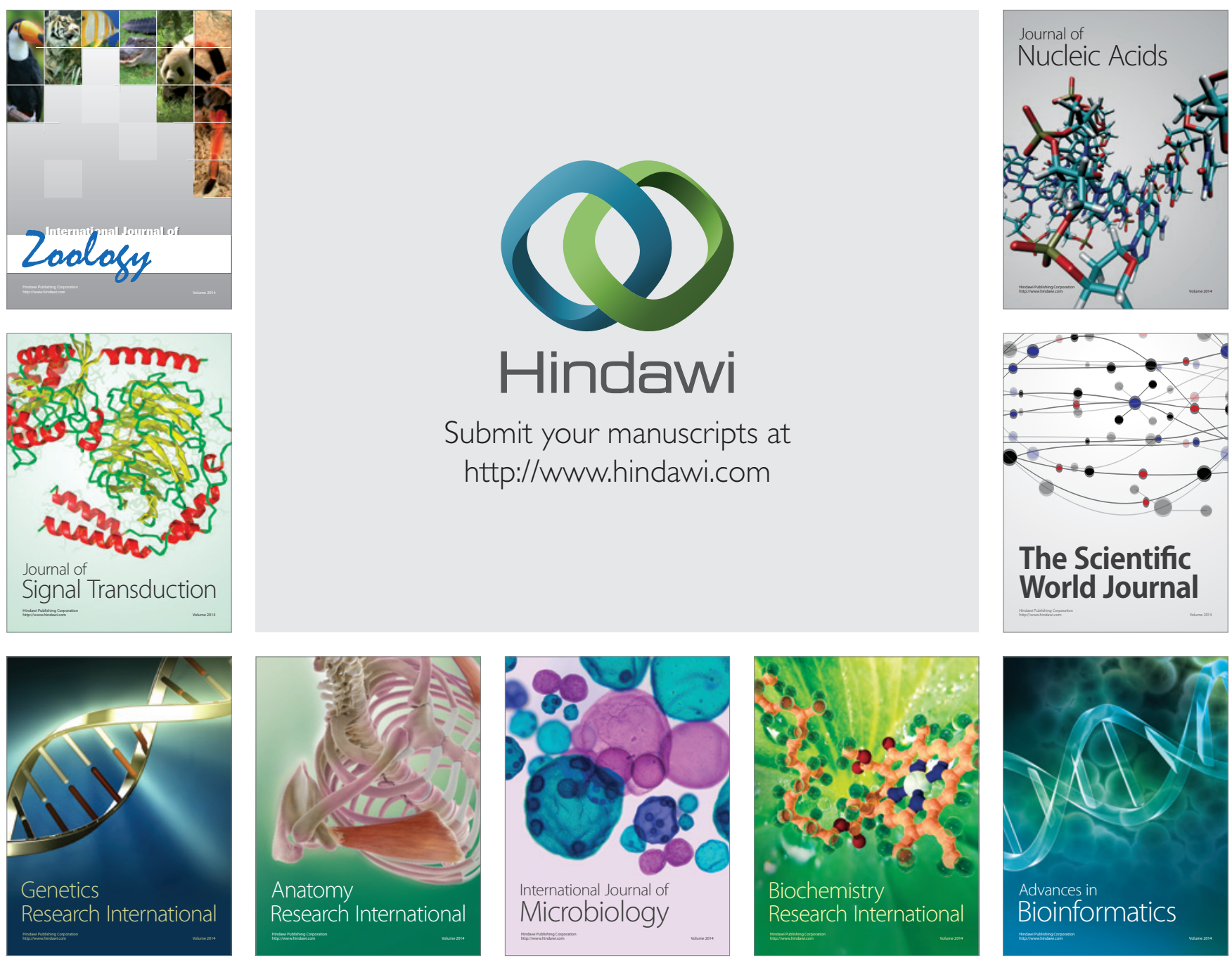

The Scientific World Journal
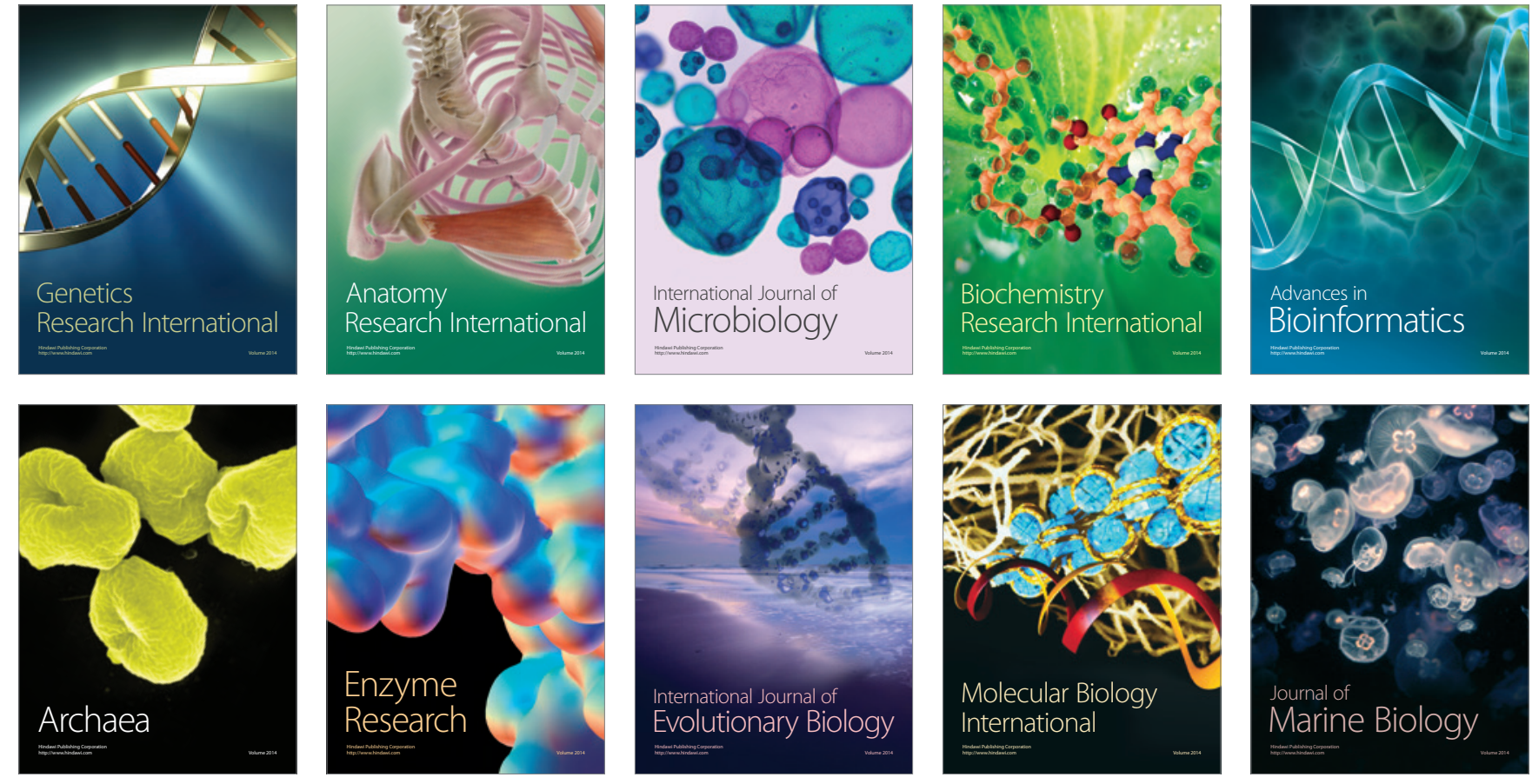